\title{
Impact of established cardiovascular disease on 10-year death after coronary revascularization for complex coronary artery disease
}

\author{
Rutao Wang ${ }^{1,2,3} \cdot$ Scot Garg ${ }^{4} \cdot$ Chao Gao ${ }^{1,2,3} \cdot$ Hideyuki Kawashima ${ }^{2,5} \cdot$ Masafumi Ono ${ }^{2,5} \cdot$ Hironori Hara ${ }^{2,5}$. \\ Robert-Jan van Geuns ${ }^{3}$. Marie-Claude Morice ${ }^{6}$. Piroze M. Davierwala ${ }^{7}$. Arie Pieter Kappetein ${ }^{8}$. David R. Holmes ${ }^{9}$. \\ William Wijns ${ }^{2} \cdot$ Ling Tao $^{1} \cdot$ Yoshinobu Onuma ${ }^{2} \cdot$ Patrick W. Serruys ${ }^{2,10}$
}

Received: 11 May 2021 / Accepted: 12 August 2021 / Published online: 25 August 2021

(c) The Author(s) 2021

\begin{abstract}
Aims To investigate the impact of established cardiovascular disease (CVD) on 10-year all-cause death following coronary revascularization in patients with complex coronary artery disease (CAD).

Methods The SYNTAXES study assessed vital status out to 10 years of patients with complex CAD enrolled in the SYNTAX trial. The relative efficacy of PCI versus CABG in terms of 10-year all-cause death was assessed according to co-existing CVD.

Results Established CVD status was recorded in 1771 (98.3\%) patients, of whom 827 (46.7\%) had established CVD. Compared to those without CVD, patients with CVD had a significantly higher risk of 10 -year all-cause death (31.4\% vs. $21.7 \%$; adjusted HR: 1.40; 95\% CI 1.08-1.80, $p=0.010)$. In patients with CVD, PCI had a non-significant numerically higher risk of 10-year all-cause death compared with CABG (35.9\% vs. 27.2\%; adjusted HR: 1.14; 95\% CI 0.83-1.58, $p=0.412$ ). The relative treatment effects of PCI versus CABG on 10-year all-cause death in patients with complex CAD were similar irrespective of the presence of CVD ( $p_{\text {-interaction }}=0.986$ ). Only those patients with CVD in $\geq 2$ territories had a higher risk of 10-year all-cause death (adjusted HR: 2.99, 95\% CI 2.11-4.23, $p<0.001$ ) compared to those without CVD.

Conclusions The presence of CVD involving more than one territory was associated with a significantly increased risk of 10-year all-cause death, which was non-significantly higher in complex CAD patients treated with PCI compared with CABG. Acceptable long-term outcomes were observed, suggesting that patients with established CVD should not be precluded from undergoing invasive angiography or revascularization.

Trial registration SYNTAX: ClinicalTrials.gov reference: NCT00114972. SYNTAX Extended Survival: ClinicalTrials.gov reference: NCT03417050.
\end{abstract}

Patrick W. Serruys

patrick.w.j.c.serruys@gmail.com

1 Department of Cardiology, Xijing Hospital, Xi' an, China

2 Department of Cardiology, National University of Ireland, Galway (NUIG), P.O. University Road, Galway H91 TK33, Ireland

3 Department of Cardiology, Radboud University Medical Center, Nijmegen, The Netherlands

4 East Lancashire Hospitals NHS Trust, Blackburn, Lancashire, UK

5 Department of Cardiology, Amsterdam Universities Medical Centers, Location Academic Medical Center, University of Amsterdam, Amsterdam, The Netherlands
6 ICPS Ramsay-Generale de Sante, Massy, France

7 Department of Cardiac Surgery, Heart Centre Leipzig, Leipzig, Germany

8 Department of Cardiothoracic Surgery, Erasmus University Medical Centre, Rotterdam, The Netherlands

9 Mayo Clinic, Rochester, MN, USA

10 NHLI, Imperial College London, London, UK 


\section{Graphic abstract}
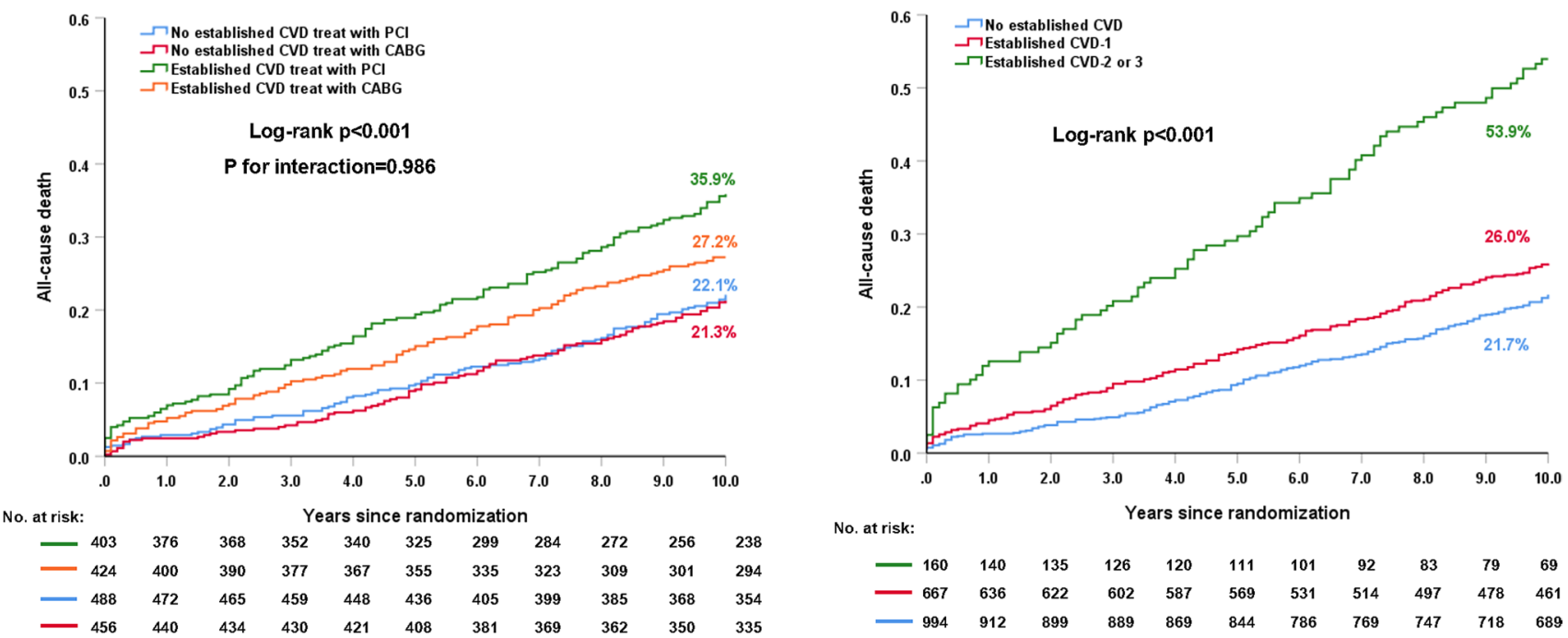

Central illustration: The presence of established CVD, especially involving more than one territory, was associated with a significantly increased risk of 10-year all-cause death. Acceptable long-term outcomes amongst patients with complex CAD and established CVD were observed, suggesting that patients with established CVD should not be precluded from undergoing invasive angiography or revascularization, which could improve their morbidity and mortality. PCI had a numerically higher but not significant risk of 10-year all-cause death compared with CABG in patients with de novo 3VD and/or LMCAD.

Keywords CABG $\cdot$ Cardiovascular disease $\cdot$ Left main coronary artery disease $\cdot$ PCI $\cdot$ Three-vessel disease

\author{
Abbreviations \\ CABG Coronary bypass artery grafting \\ CAD Coronary artery disease \\ CVD Cardiovascular disease \\ CI Confidence interval \\ HR Hazard ratio \\ LMCAD Left main coronary artery disease \\ MACCE Major adverse cardiovascular and cerebrovas- \\ cular events \\ MI Myocardial infarction \\ PCI Percutaneous coronary intervention \\ PVD Peripheral vascular disease \\ 3VD Three-vessel disease
}

\section{Introduction}

Atherothrombosis is a systemic disease, usually involving more than one arterial bed, which has been termed poly-vascular disease $[1,2]$. Patients with coronary artery disease $(\mathrm{CAD})$ frequently have co-existing peripheral vascular disease (PVD) and/or cerebrovascular disease, with these patients at increased risk of in-hospital and mid-term adverse events [3-6]. However, to date, most available data are derived from cardiovascular prevention studies [7], and only limited data exist on outcomes following revascularization of patients with CAD and co-existing poly-vascular disease $[8,9]$. Notably, these studies show that these vascular patients were less likely to undergoing invasive revascularization [10], and following percutaneous coronary intervention (PCI), they have a higher risk of short- and mid-term mortality $[8,9,11,12]$. The impact of established cardiovascular disease (CVD) on very long-term all-cause death in patents with complex CAD following coronary revascularization also remains unclear. In addition, the optimal revascularization strategy for these patients has not been fully investigated.

The SYNTAX Extended Survival (SYNTAXES) study collected the 10-year survival status in $94 \%$ of the 1800 patients with de novo three-vessel disease (3VD) and/or left main coronary artery disease (LMCAD) who were originally randomised to PCI or coronary artery bypass grafting (CABG) in the SYNTAX trial [13]. Given the inclusion and exclusion criteria, the SYNTAX trial provides an enriched population to evaluate the effect of established CVD on outcomes after coronary revascularization in patients with 
complex CAD. The aims of the present study were, therefore, (1) to investigate the impact of established CVD on 10-year all-cause death following coronary revascularization in patients with complex CAD; (2) to examine the relative treatment effect of PCI versus CABG on 10-year all-cause death in patients with complex CAD and established CVD; and (3) to estimate the impact of the degree of established CVD on 10-year all-cause death.

\section{Methods}

\section{Study design and population}

The design and the primary results of the SYNTAX trial have been published previously [14-16]. Briefly, the SYNTAX trial (NCT00114972) was an international, multicentre, randomised controlled trial which randomised allcomers patients with de novo 3VD and/or LMCAD, deemed eligible for both PCI and CABG, in a 1:1 fashion to either CABG $(n=897)$ or PCI $(n=903)$ with the TAXUS Express paclitaxel-drug eluting stents (Boston Scientific Corporation, Marlborough, MA, USA). The SYNTAX trial completed patient follow-up at 5 years [16]. The SYNTAXES study (NCT03417050) was an investigator-driven initiative that extended follow-up and aimed to evaluate vital status up to 10 years [13], funded by the German Heart Research Foundation (GHF; Frankfurt am Main, Germany). Followup was performed in accordance with local regulations of each participating centre and complied with the Declaration of Helsinki.

\section{Definitions and endpoints}

In the present study, the cohort was stratified according to those with and without established CVD as reported by the investigator at the time of enrolment, and defined as $\geq 1$ prior myocardial infarction (MI), prior cerebrovascular disease, or established PVD [1, 12]. The degree of established CVD was defined based on the extent of prior vascular disease with CVD-1 defined as patients having only one of a previous MI, cerebrovascular disease, or PVD; CVD-2 patients having two of these three conditions and CVD-3 patients having all three of these diagnoses. Only a few patients had vascular disease in three territories, so they were combined with patients in the CVD-2 group.

The primary endpoint of the SYNTAXES study was 10 -year all-cause death. The secondary endpoint was allcause death at maximum available follow-up. The 5-year rate of major adverse cardiovascular and cerebrovascular events (MACCE, defined as a composite endpoint of allcause death, cerebrovascular accident, MI or repeat revascularization, the primary endpoint of the SYNTAX trial) according to the presence or absence of established CVD was also explored in the present study. Vital status was confirmed by contact with medical care personnel or by electronic healthcare record review and national death registries.

\section{Statistical analysis}

Continuous variables are reported as mean \pm standard deviation, and were compared using Student's $t$ test or Mann-Whitney $U$ test. Categorical variables are shown as percentages and numbers, and were compared using Chisquare tests, or Fisher's exact test when appropriate. The Kaplan-Meier method was used to estimate cumulative event rates, with the log-rank test used to assess differences between groups. Cox proportional hazards regression was used to calculate hazard ratios (HRs) with $95 \%$ confidence intervals (CI), and interaction tests were performed to assess the differences in the treatment effect of revascularization strategy in patients with and without established CVD. Multivariable analysis was performed to investigate whether established CVD was an independent predictor of all-cause death at 10 years. The Cox proportional hazards regression model included the following covariates: age, gender, body mass index, medically treated diabetes, hypertension, chronic obstructive pulmonary disease, left ventricular ejection fraction, creatinine clearance $(\mathrm{ml} / \mathrm{min})$, disease type (3VD or LMCAD), and the anatomical SYNTAX score, with all these variables selected based on prior knowledge of their association with clinical outcomes [17]. All analyses were performed using SPSS Statistics, version 25 (IBM Corp., Armonk, 281 N.Y., USA) and a $p$ value of $<0.05$ was considered statistically significant.

\section{Results}

\section{Baseline and procedural characteristics}

A total of 1800 patients were randomised in the SYNTAX trial, of which 29 had at least one missing piece of data on the status of co-existing established CVD. The study cohort, therefore, comprised of 1771 (98.3\%) patients, of whom 827 (46.7\%) had documented established CVD (Online Fig. 1). The median duration of follow-up was 11.2 years (IQR 7.9-12.1) overall and 11.8 years (11.0-12.3) in survivors. Patients with established CVD were older and had significantly higher rates of insulin treated diabetes, chronic obstructive pulmonary disease, renal impairment, congestive heart failure, and unstable angina. They had higher EuroSCOREs, Parsonnet scores, anatomical SYNTAX scores, and had more $3 \mathrm{VD}$, lesions, total occlusions, bifurcations, stents, and had a longer total stent length (Online Table 1). They were less likely to have hypertension, had lower 
creatinine clearance and left ventricular ejection fraction (Online Table 1).

Patients with established CVD who underwent PCI were more likely to be female and had higher rates of hypertension and renal impairment compared to those underwent CABG (Table 1). Other baseline characteristics were well balanced between patients with established CVD treated with PCI or CABG.

\section{All-cause death according to established CVD}

All-cause death according to established CVD is shown in Table 2. Compared to those without a history of established CVD, patients with established CVD had a significantly higher risk of 10 -year all-cause death $(31.4 \%$ vs. $21.7 \%$; adjusted HR: 1.40; 95\% CI 1.08-1.80; $p=0.010$, Fig. 1a). Similar results were observed at maximum follow-up (43.6\% vs. $37.8 \%$; adjusted HR: 1.42 ; 95\% CI 1.23-1.80; $p=0.003)$. Landmark analysis showed that the presence of established CVD resulted in a higher risk of all-cause death at 5 years (16.9\% vs. 9.3\%; adjusted HR: 1.87 ; 95\% CI 1.26-2.75; $p=0.002$ ), and a numerically higher (but not significant) rate of all-cause death between 5 and 10 years $(17.4 \%$ vs. 13.7\%; adjusted HR: 1.10 ; 95\% CI 0.78-1.55; $p=0.599)$.

\section{All-cause death according to revascularization strategy}

In patients with established CVD, PCI had a higher crude rate of all-cause death at 10 years compared with CABG (35.9\% vs. $27.2 \%$; HR: 1.38 ; 95\% CI 1.08-1.77, Logrank $p=0.01$ ). However, after adjustment for confounders, no significant difference between PCI and CABG was observed (adjusted HR: 1.14 ; 95\% CI 0.83-1.58, $p=0.412$, Table 3, Fig. 2a). In patients without established CVD, PCI had a comparable rate of 10-year all-cause death compared to CABG (22.1\% vs. $21.3 \%$, adjusted HR: 1.11 ; $95 \%$ CI $0.75-1.63, p=0.601$, Table 3, Fig. 2b). The risk of 10-year all-cause death was similar between PCI and CABG irrespective of the presence of established CVD $\left(p_{\text {-interaction }}=0.986\right.$, Table 3$)$. Similar observations were found at maximum follow-up (Table 3 ).

\section{All-cause death according to anatomical SYNTAX score}

In patients with established CVD, a numerically higher rate of all-cause death at 10 years and at maximum follow-up was seen following PCI compared with CABG in all anatomical SYNTAX score tertiles (Online Tables 2 and 3). In contrast, amongst patients without established CVD, there were no significant differences in all-cause death at 10 years and at maximum follow-up between PCI and CABG in any anatomical SYNTAX score tertile (Online Tables 2 and 3). No significant interaction was observed between the modality of revascularization and SYNTAX score tertile on 10-year all-cause death amongst patients with $\left(p_{\text {-interaction }}=0.472\right)$ or without established CVD $\left(p_{\text {-interaction }}=0.521\right.$, Online Table 2).

\section{All-cause death according to extent of established CVD}

After adjustment for confounders, compared to those without established CVD, patients with one territory of CVD were found to have a trend for an increased risk of 10-year all-cause death, whilst the risk was a significant 2.9 times higher amongst those having more than one territory involved (Fig. 1b, Table 4). The HR for mortality decreased over time from 3.44 to 2.99 and then 2.97 at 5-year, 10-year and maximum follow-up, respectively (Table 4).

After adjustment for confounders, prior MI was not an independent predictor of all-cause death, whereas both prior cerebrovascular disease and PVD were independent predictors of all-cause death at 10 years and at maximum follow-up (Table 5).

\section{SYNTAX score II 2020 for predicting death at 10 years in patients with and without established CVD}

Figure 3 shows ranked individual differences $(n=827)$ in predicted mortalities for patients with established CVD undergoing either PCI (blue dashed line) or CABG (red dashed line). In terms of ranking, there are 614 patients with higher predicted mortality after PCI than CABG, following which a crossover point in predicted mortalities (equipoise) is reached; beyond this point are 213 patients whose predicted mortality is lower with PCI than CABG. The solid lines in Fig. 3 depict, in a spline regression (LOESS) [18], the observed mortality after PCI or CABG. Notably, these observed mortalities crossover at the 663rd ranked patient suggesting only that specific patient had the same prognosis after PCI or CABG. The remaining 164 patients had higher observed mortality after surgery compared to PCI. Therefore, in contrast to the neutral "average treatment effect" observed in patients with established CVD at 10 years with either CABG or PCI, the SYNTAX score II 2020 clearly identifies individuals who derive a treatment-specific survival benefit. 
Table 1 Baseline and procedural characteristics according to established CVD and revascularization strategy

\begin{tabular}{|c|c|c|c|c|c|c|}
\hline & \multicolumn{3}{|c|}{ Established CVD $(n=827)$} & \multicolumn{3}{|c|}{ Without established CVD $(n=944)$} \\
\hline & PCI $(n=403)$ & CABG $(n=424)$ & $\begin{array}{l}p \text { (PCI vs. } \\
\text { CABG) }\end{array}$ & PCI $(n=488)$ & CABG $(n=456)$ & $\begin{array}{l}p \text { (PCI vs. } \\
\text { CABG) }\end{array}$ \\
\hline Age (year) & $66 \pm 9.1$ & $65.7 \pm 9.7$ & 0.588 & $64.5 \pm 10.1$ & $64.2 \pm 9.7$ & 0.562 \\
\hline Body mass index $\left(\mathrm{kg} / \mathrm{m}^{2}\right)$ & $28.1 \pm 5.1$ & $27.6 \pm 4.4$ & 0.101 & $28.1 \pm 4.5$ & $28.3 \pm 4.6$ & 0.499 \\
\hline Gender & & & 0.006 & & & 0.573 \\
\hline Female & $25.8(104 / 403)$ & $17.9(76 / 424)$ & & $21.9(107 / 488)$ & $23.5(107 / 456)$ & \\
\hline Male & $74.2(299 / 403)$ & $82.1(348 / 424)$ & & $78.1(381 / 488)$ & $76.5(349 / 456)$ & \\
\hline Medically treated diabetes & $27.3(110 / 403)$ & $25.2(107 / 424)$ & 0.501 & $24(117 / 488)$ & $24.1(110 / 456)$ & 0.958 \\
\hline On insulin & $13.2(53 / 403)$ & $12(51 / 424)$ & 0.626 & $7(34 / 488)$ & $8.6(39 / 456)$ & 0.362 \\
\hline Hypertension & $66.5(268 / 403)$ & $59(250 / 424)$ & 0.025 & $70.9(346 / 488)$ & $68.6(313 / 456)$ & 0.449 \\
\hline Dyslipidemia & $78.6(315 / 401)$ & $79.3(334 / 421)$ & 0.784 & $78.9(381 / 483)$ & $76.1(343 / 451)$ & 0.301 \\
\hline Current smoker & $19.6(79 / 403)$ & $22.9(96 / 420)$ & 0.254 & $17.6(86 / 488)$ & $20.5(93 / 453)$ & 0.256 \\
\hline Chronic obstructive pulmonary disease & $10.7(43 / 403)$ & $9.2(39 / 424)$ & 0.479 & $5.3(26 / 488)$ & $8.8(40 / 456)$ & 0.038 \\
\hline Impaired renal function & $22.6(91 / 403)$ & $18.9(80 / 424)$ & 0.002 & $15.2(74 / 488)$ & $14(64 / 456)$ & 0.002 \\
\hline Creatinine clearance $(\mathrm{ml} / \mathrm{min})$ & $84.6 \pm 36.2$ & $83.9 \pm 30.7$ & 0.776 & $88.4 \pm 35.3$ & $87.6 \pm 28.1$ & 0.714 \\
\hline Left ventricular ejection fraction & $56.1 \pm 13$ & $55.7 \pm 13.1$ & 0.719 & $61.6 \pm 12.1$ & $60.8 \pm 12.5$ & 0.414 \\
\hline Congestive heart failure & $5.5(22 / 401)$ & $8.2(34 / 415)$ & 0.126 & $2.7(13 / 488)$ & $2.4(11 / 450)$ & 0.832 \\
\hline Clinical presentation & & & 0.599 & & & 0.850 \\
\hline Silent ischaemia & $16.9(68 / 403)$ & $18.9(80 / 424)$ & & $11.7(57 / 488)$ & $10.5(48 / 456)$ & \\
\hline Stable angina & $47.1(190 / 403)$ & $48.1(204 / 424)$ & & $65(317 / 488)$ & $65.6(299 / 456)$ & \\
\hline Unstable angina & $36(145 / 403)$ & $33(140 / 424)$ & & $23.4(114 / 488)$ & $23.9(109 / 456)$ & \\
\hline Euro SCORE & $5 \pm 2.7$ & $4.8 \pm 2.8$ & 0.564 & $2.8 \pm 2.1$ & $2.8 \pm 2.2$ & 0.927 \\
\hline Parsonnet SCORE & $9.3 \pm 6.9$ & $9.2 \pm 7.2$ & 0.789 & $7.9 \pm 6.9$ & $7.6 \pm 6.3$ & 0.559 \\
\hline Disease extent & & & 0.136 & & & 0.451 \\
\hline $3 \mathrm{VD}$ & $61.5(248 / 403)$ & $66.5(282 / 424)$ & & $59.2(289 / 488)$ & $56.8(259 / 456)$ & \\
\hline LMCAD & $38.5(155 / 403)$ & $33.5(142 / 424)$ & & $40.8(199 / 488)$ & $43.2(197 / 456)$ & \\
\hline Disease extent & & & 0.342 & & & 0.318 \\
\hline LMCAD only & $3.2(13 / 403)$ & $2.1(9 / 424)$ & & $5.9(29 / 488)$ & $8.1(37 / 455)$ & \\
\hline $\mathrm{LMCAD}+1 \mathrm{VD}$ & $6(24 / 403)$ & $5.4(23 / 424)$ & & $8.8(43 / 488)$ & $10.5(48 / 455)$ & \\
\hline $\mathrm{LMCAD}+2 \mathrm{VD}$ & $10.7(43 / 403)$ & $12(51 / 424)$ & & $14.1(69 / 488)$ & $11.2(51 / 455)$ & \\
\hline $\mathrm{LMCAD}+3 \mathrm{VD}$ & $18.6(75 / 403)$ & $13.9(59 / 424)$ & & $11.9(58 / 488)$ & $13.4(61 / 455)$ & \\
\hline $2 \mathrm{VD}$ & $1.7(7 / 403)$ & $1.2(5 / 424)$ & & $2(10 / 488)$ & $3.1(14 / 455)$ & \\
\hline $3 \mathrm{VD}$ & $59.8(241 / 403)$ & $65.3(277 / 424)$ & & $57.2(279 / 488)$ & $53.6(244 / 455)$ & \\
\hline Anatomical SYNTAX score & $29.3 \pm 11.6$ & $29.3 \pm 10.9$ & 0.960 & $27.6 \pm 11.3$ & $28.8 \pm 11.7$ & 0.113 \\
\hline Number of lesions & $4.6 \pm 1.8$ & $4.6 \pm 1.7$ & 0.965 & $4.1 \pm 1.8$ & $4.2 \pm 1.9$ & 0.436 \\
\hline Any total occlusion & $0.3 \pm 0.4$ & $0.3 \pm 0.4$ & 0.866 & $0.2 \pm 0.4$ & $0.2 \pm 0.4$ & 0.252 \\
\hline Any bifurcation & $0.7 \pm 0.4$ & $0.8 \pm 0.4$ & 0.423 & $0.7 \pm 0.5$ & $0.7 \pm 0.5$ & 0.859 \\
\hline Number of stents & $4.8 \pm 2.2$ & - & & $4.5 \pm 2.3$ & - & \\
\hline Total stent length per patient & $90.3 \pm 48.3$ & - & & $82.6 \pm 47.2$ & - & \\
\hline Off pump CABG & - & $13(55 / 424)$ & & - & $14.9(68 / 456)$ & \\
\hline Number of total conduits & - & $2.8 \pm 0.7$ & & - & $2.7 \pm 0.7$ & \\
\hline Number of arterial conduits & - & $1.4 \pm 0.6$ & & - & $1.4 \pm 0.7$ & \\
\hline Number of venous conduits & - & $1.4 \pm 0.9$ & & - & $1.3 \pm 0.9$ & \\
\hline LIMA use & - & $80.7(342 / 424)$ & & - & $83.3(380 / 456)$ & \\
\hline Complete revascularization & $55.2(222 / 402)$ & $59.8(244 / 408)$ & 0.187 & $57.3(276 / 482)$ & $65.6(292 / 445)$ & 0.009 \\
\hline
\end{tabular}

$C A B G$ coronary bypass artery grafting, $C V D$ cardiovascular disease, $L M C A D$ left main coronary artery disease, $P C I$ percutaneous coronary intervention, $V D$ vessel disease 
Table 2 Clinical outcomes between patients with and without established CVD

\begin{tabular}{|c|c|c|c|c|c|c|}
\hline & $\begin{array}{l}\text { Without established CVD } \\
\%(n / N)\end{array}$ & $\begin{array}{l}\text { Established CVD } \\
\%(n / N)\end{array}$ & Unadjusted HR 95\% CI & $p$ & $\begin{array}{l}\text { Adjusted HR } \\
95 \% \text { CI }\end{array}$ & Adjusted $p$ \\
\hline \multicolumn{7}{|l|}{$0-5$ years } \\
\hline MACCE & $30.4 \%(278 / 944)$ & $35.3 \%(275 / 827)$ & $1.18(0.998-1.39)$ & 0.053 & $1.20(0.95-1.51)$ & 0.122 \\
\hline Death, MI or stroke & $15.3 \%(135 / 944)$ & $24.0 \%(188 / 827)$ & $1.69(1.35-2.11)$ & $<0.001$ & $1.56(1.14-2.14)$ & 0.005 \\
\hline All-cause death & $9.3 \%(87 / 944)$ & $16.9 \%(139 / 827)$ & $2.05(1.55-2.70)$ & $<0.001$ & $1.87(1.26-2.75)$ & 0.002 \\
\hline Cardiac death & $4.4 \%(39 / 944)$ & $10.7 \%(80 / 827)$ & $2.47(1.68-3.62)$ & $<0.001$ & $2.24(1.30-3.84)$ & 0.003 \\
\hline MI & $5.4 \%(49 / 944)$ & $8.8 \%(67 / 827)$ & $1.64(1.13-2.36)$ & 0.008 & $1.69(1.02-2.81)$ & 0.044 \\
\hline Stroke & $2.8 \%(25 / 944)$ & $3.5 \%(26 / 827)$ & $1.23(0.71-2.14)$ & 0.454 & $0.94(0.42-2.09)$ & 0.878 \\
\hline Revascularization & $20.8 \%(183 / 944)$ & $20.2 \%(146 / 827)$ & $0.95(0.76-1.18)$ & 0.649 & $1.08(0.81-1.45)$ & 0.608 \\
\hline \multicolumn{7}{|l|}{ 5-10 years } \\
\hline All-cause death & $13.7 \%(110 / 944)$ & $17.4 \%(113 / 827)$ & $1.31(1.005-1.70)$ & 0.045 & $1.10(0.78-1.55)$ & 0.599 \\
\hline \multicolumn{7}{|l|}{10 years } \\
\hline All-cause death & $21.7 \%(197 / 944)$ & $31.4 \%(252 / 827)$ & $1.58(1.31-1.90)$ & $<0.001$ & $1.40(1.08-1.80)$ & 0.010 \\
\hline \multicolumn{7}{|l|}{ At maximum follow-up } \\
\hline All-cause death & $37.8 \%(246 / 944)$ & $43.6 \%(310 / 827)$ & $1.58(1.33-1.86)$ & $<0.001$ & $1.42(1.23-1.80)$ & 0.003 \\
\hline
\end{tabular}

$C V D$ cardiovascular disease, $M A C C E$ major adverse cardiovascular and cerebrovascular events, $M I$ myocardial infarction
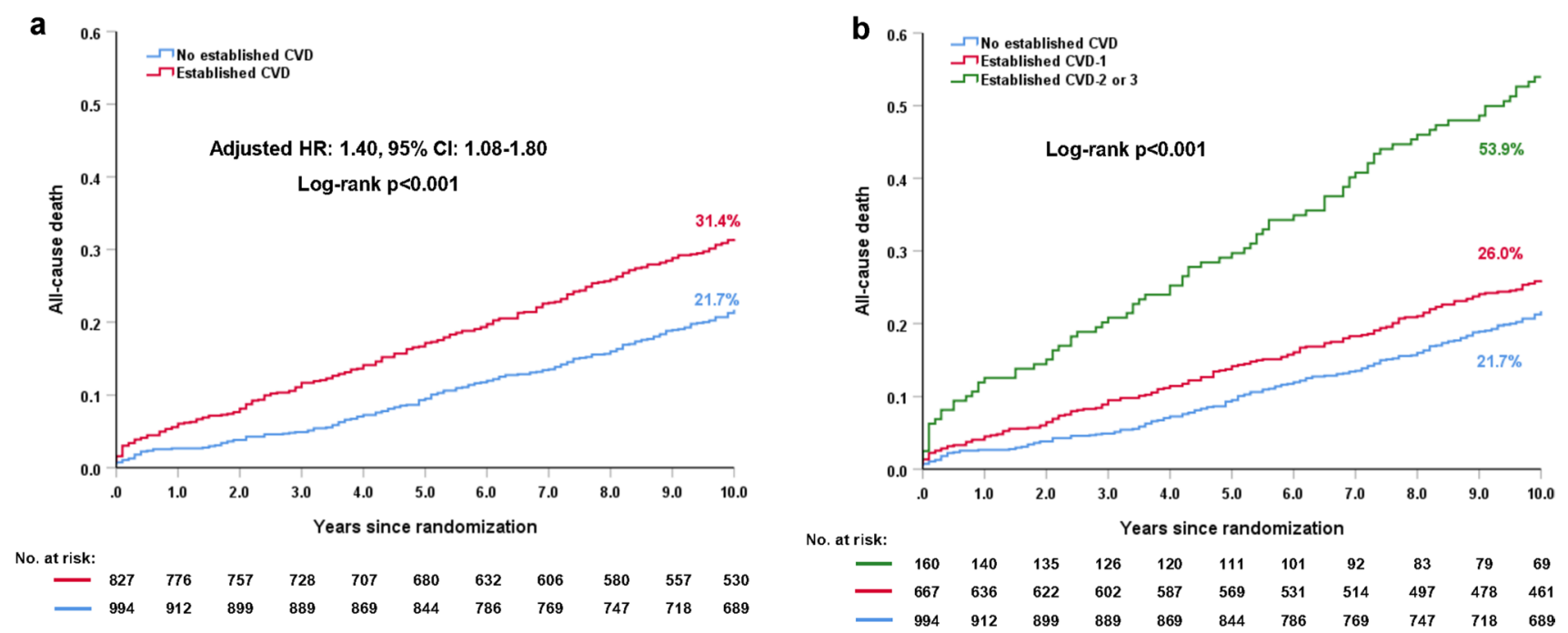

Fig. 1 Ten-year all-cause death according to the extent of established CVD. a 10-year all-cause death in patients with established CVD versus those without; b 10-year all-cause death according to the extent of established CVD

\section{Discussion}

In the present study, we assessed the impact of established CVD on 10-year all-cause death and evaluated the treatment effect of PCI versus CABG in patients with 3VD and/or LMCAD. The main findings are: (1) co-existing established CVD was common, being present in nearly half of the patients with $3 \mathrm{VD}$ and/or LMCAD; (2) patients with established CVD had a higher risk of all-cause death compared to those without, with the risk increasing according to the number of arterial beds affected; (3) the relative treatment effects of PCI versus CABG on 10-year 


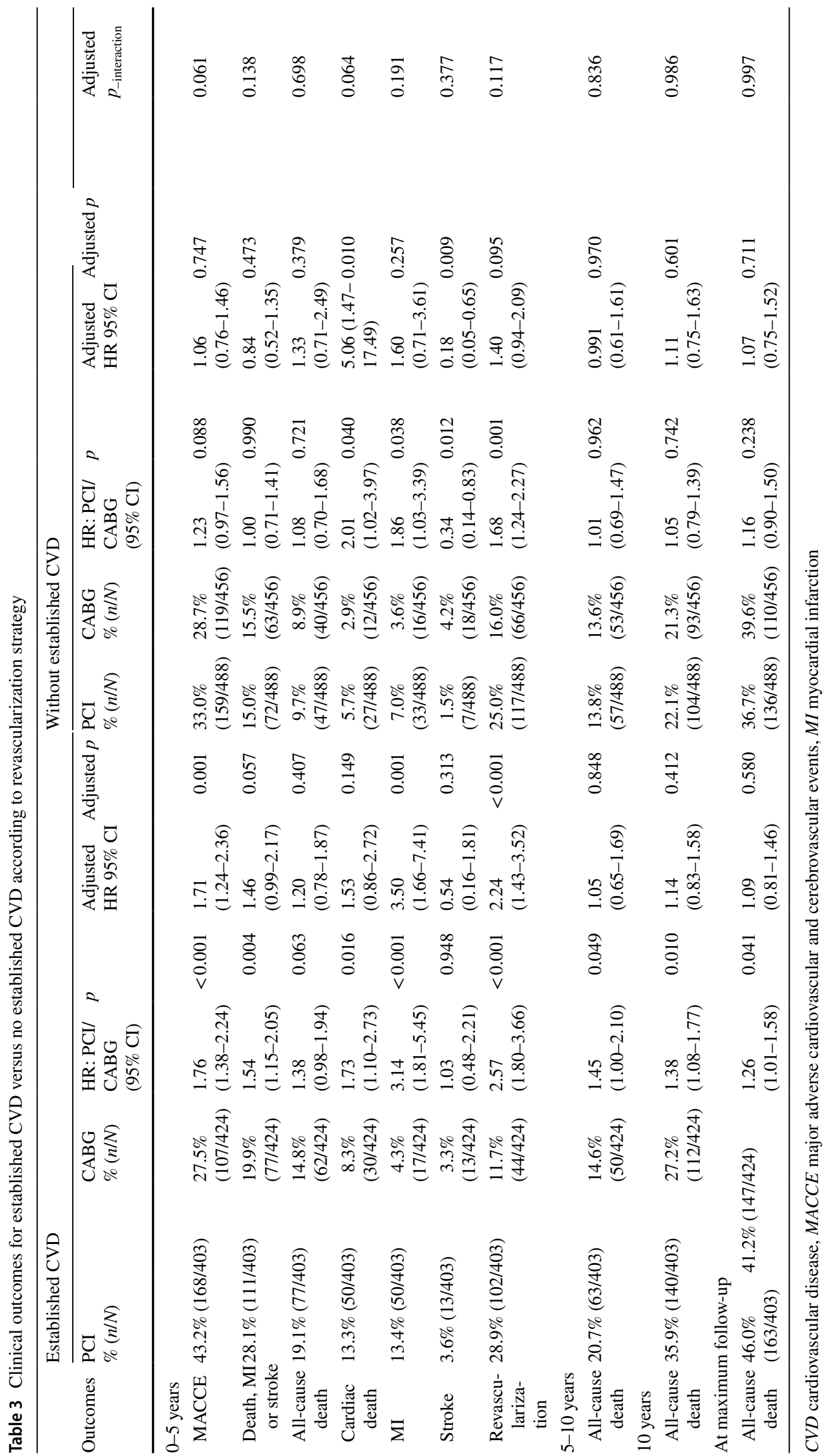



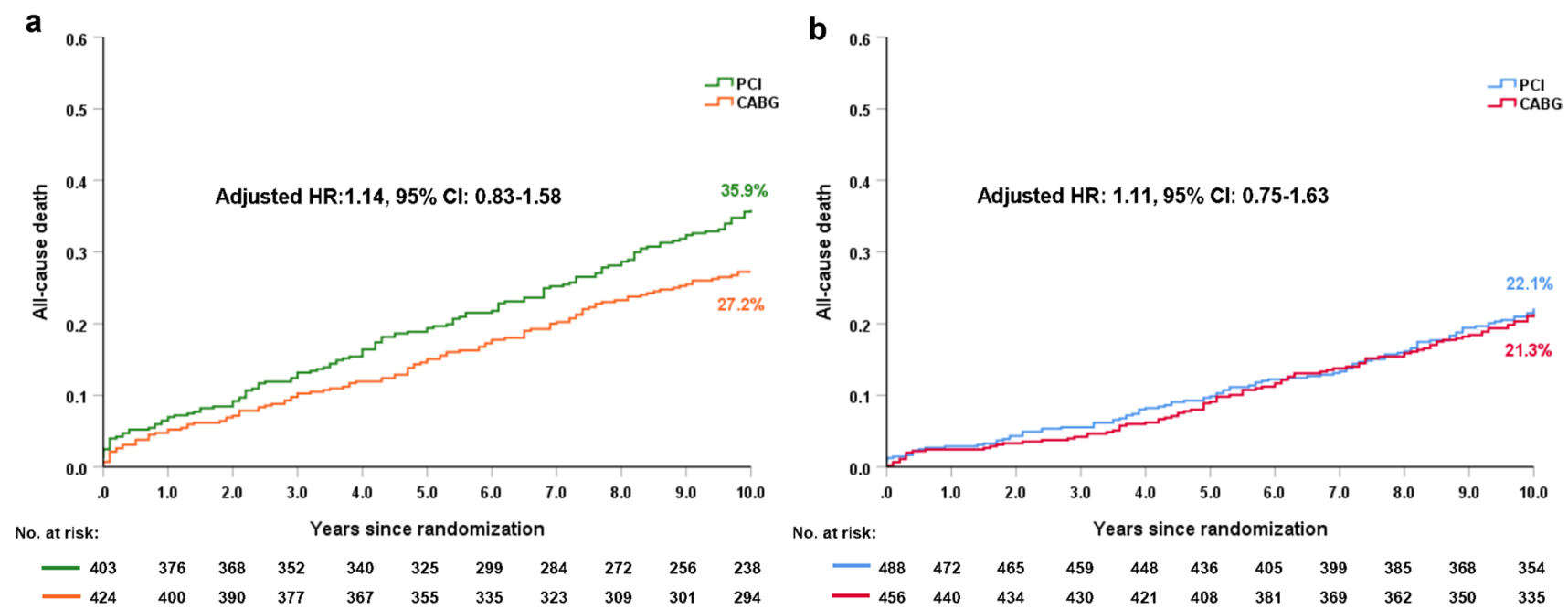

Fig. 2 Ten-year all-cause death according to revascularization strategies and established CVD. a patients with established CVD; b patients without established CVD

Table 4 All-cause death according to extent of established CVD

\begin{tabular}{|c|c|c|c|c|c|c|c|c|}
\hline All-cause death & $\begin{array}{l}\text { Unadjusted HR } \\
\text { CVD-1/no CVD }\end{array}$ & $\begin{array}{l}p(\mathrm{CVD}-1 / \\
\text { no CVD) }\end{array}$ & $\begin{array}{l}\text { Unadjusted } \\
\text { HR CVD-2/no } \\
\text { CVD }\end{array}$ & $\begin{array}{l}p(\mathrm{CVD}-2 / \\
\text { no CVD) }\end{array}$ & $\begin{array}{l}\text { Adjusted HR } \\
\text { CVD-1/no CVD }\end{array}$ & $\begin{array}{l}\text { Adjusted } \\
p \text { (CVD-1/ } \\
\text { no CVD) }\end{array}$ & $\begin{array}{l}\text { Adjusted HR } \\
\text { (CVD-2/no CVD) }\end{array}$ & $\begin{array}{l}\text { Adjusted } p \\
\text { (CVD-2/no } \\
\text { CVD) }\end{array}$ \\
\hline At 5 years & $1.54(1.15-2.07)$ & 0.004 & $3.67(2.57-5.23)$ & $<0.001$ & $1.52(1.00-2.31)$ & 0.051 & $3.44(2.09-5.68)$ & $<0.001$ \\
\hline $\begin{array}{l}\text { Between } 5 \text { and } \\
10 \text { years }\end{array}$ & $1.03(0.77-1.38)$ & 0.835 & $2.89(1.99-4.19)$ & $<0.001$ & $0.88(0.60-1.28)$ & 0.508 & $2.65(1.60-4.39)$ & $<0.001$ \\
\hline At 10 years & $1.26(1.02-1.54)$ & 0.029 & $3.23(2.5-4.18)$ & $<0.001$ & $1.12(0.85-1.48)$ & 0.421 & $2.99(2.11-4.23)$ & $<0.001$ \\
\hline $\begin{array}{l}\text { At maximum } \\
\text { follow-up }\end{array}$ & $1.30(1.08-1.56)$ & 0.005 & $3.08(2.43-3.91)$ & $<0.001$ & $1.17(0.91-1.51)$ & 0.212 & $2.97(2.14-4.15)$ & $<0.001$ \\
\hline
\end{tabular}

$C V D$ cardiovascular disease, $H R$ hazard ratio, $V D$ vessel disease

Table 5 All-cause death according to the three affected arterial beds

\begin{tabular}{|c|c|c|c|c|c|c|}
\hline & \multicolumn{2}{|l|}{ Prior MI } & \multicolumn{2}{|c|}{ Prior cerebrovascular disease } & \multicolumn{2}{|l|}{ PVD } \\
\hline & Adjusted HR (95\% CI) & Adjusted $p$ & Adjusted HR (95\% CI) & Adjusted $p$ & Adjusted HR (95\% CI) & Adjusted $p$ \\
\hline At 5 years & $1.29(0.87-1.90)$ & 0.203 & $1.50(0.99-2.26)$ & 0.053 & $2.91(1.94-4.37)$ & $<0.001$ \\
\hline At 10 years & $1.06(0.81-1.39)$ & 0.670 & $1.63(1.22-2.17)$ & 0.001 & $2.45(1.81-3.31)$ & $<0.001$ \\
\hline At maximum follow-up & $0.91(0.71-1.18)$ & 0.481 & $1.67(1.28-2.19)$ & $<0.001$ & $2.26(1.69-3.01)$ & $<0.001$ \\
\hline
\end{tabular}

$M I$ myocardial infarction, $P V D$ peripheral vascular disease

all-cause death were similar irrespective of whether established CVD was present or not.

Given the common etiologies, it is not surprising that atherosclerosis frequently involves multiple vascular beds. In the REACH (The Reduction of Atherothrombosis for Continued Health) Registry, $15.9 \%$ of patients with symptomatic atherothrombosis had symptomatic poly-vascular disease [1]. The prevalence of co-existing established CVD in the current study is higher than that reported in prior randomised studies of PCI, PCI versus CABG and surgical registries $[12,19,20]$. This difference reflects the complexity of CAD which was required to be enrolled in the SYNTAX study, and suggests these patients may have a more malignant diffuse form of atherosclerosis with extensive widespread inflammation [21]. Consequently, the rates of statin and ACE-I/ARB use are disappointing, considering these are the cornerstones of managing atherosclerotic disease [22, 23]. Propensity-matched data comparing patients with LMCAD treated with CABG in the SYNTAX and EXCEL study have already hypothesised that the significant 
Fig. 3 The individual difference between predicted mortality (dashed lines) using the SYNTAX Score II 2020 and the individual observed mortality (solid lines), between PCI and CABG in patients with established CVD. Blue dashed line represents the predicted mortality after PCI; red dashed line represents the predicted mortality after $\mathrm{CABG}$; blue solid line represents the observed mortality after PCI; red solid line represents the observed mortality after CABG

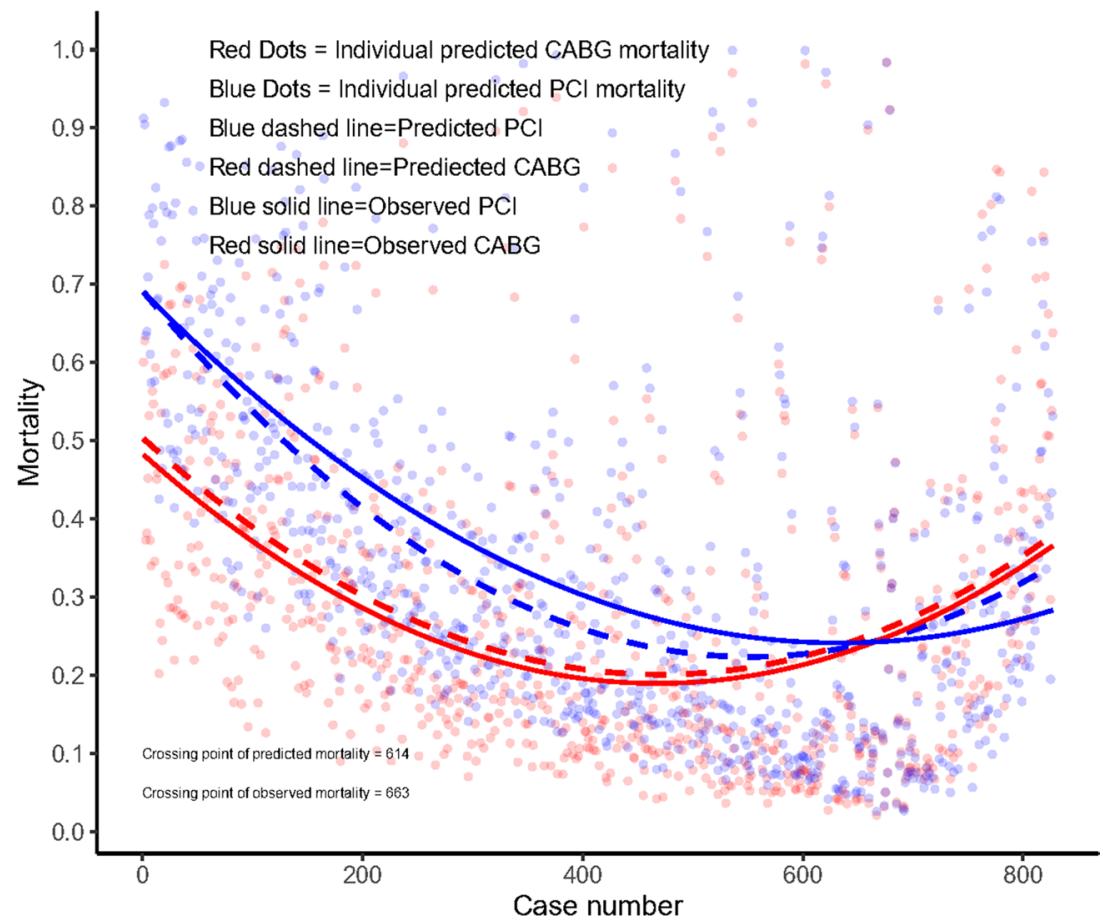

temporal improvements in the prescribing of secondary preventative therapies at discharge and 3-year follow-up in the EXCEL study drove many of the improved clinical outcomes observed in EXCEL [24].

Numerous studies have shown a correlation between the presence of established CVD and higher in-hospital and mid-term adverse outcomes following coronary revascularization [3, 4, 10, 12]. Consequently, although these patients represent a higher risk profile, studies indicate they are less likely to receive invasive management (coronary angiography or revascularization) $[3,10]$ with some reporting diagnostic cardiac catheterization rates of only 40-60\% amongst older patients with non-STEMI and co-existing CVD [25]. Data on the impact of established CVD on very long-term all-cause death post-revascularization are limited, especially in patients with complex CAD, and to our knowledge, our study is the first to evaluate this.

Post-PCI, an observational study with a mean follow-up of 7.3 years showed that established CVD was associated with an increased risk of morbidity and mortality [11]. In the Global Leaders study, the largest PCI trial conducted to-date, patients with established CVD had higher rates of all-cause death, MI, stroke and revascularization with no significant differences in bleeding at 2 years [12]. Post-CABG, retrospective studies by $\mathrm{Chu}$ et al. and Nakamura et al. have both shown that symptomatic PVD is associated with poorer survival at 9- and 10-year follow-ups, respectively [26, 27]. Overall, after coronary revascularization (PCI or CABG), Morikami et al. found that established CVD was associated with higher adverse outcomes, which was mainly driven by the increased risk for non-coronary cardiovascular events [8]. In the BARI study, 5-year survival was $75.8 \%$ in patients with CVD and $90.2 \%$ for those without $(p<0.001)$ [20]. Despite these data, our study has shown acceptable adjusted long-term outcomes amongst patients with complex CAD and established CVD, which collectively represent a very high-risk population, suggesting that these patients should not be precluded from undergoing invasive angiography or coronary revascularization, which could improve their morbidity and mortality.

Our results show that the risk of mortality increases with the number of arterial beds involved, however, in our analysis, compared to those without established CVD, patients with only one affected arterial bed only had a trend for higher 10-year all-cause death, a result inconsistent with previous findings $[3,11,28,29]$. Possible reasons for this discrepancy are multifactorial and include the differences in the enrolled populations, with our patients having very complex CAD, representing a higher risk population. The most plausible reason, however, is that prior MI (the commonest affected arterial bed amongst patients with established CVD in this study) was not found to be an independent predictor of all-cause death. Moreover, prior studies were mostly from large-scale observational studies, whereas our analysis, with a relatively limited sample size, may not have had adequate statistical power to detect the modest risk between groups. Studies with larger sample sizes in this high-risk population are, therefore, warranted to explore these outstanding issues. Finally, the HR for all-cause death in patients with more than one diseased arterial bed decreased over time 
(Table 4), indicating that established CVD increased the cumulative risk of all-cause death during the early part of follow-up but had less impact long term. These early events may be procedure related, with the reduced hazard over time reflective of the accumulated prognostic benefit of secondary preventative medications. The 10-year follow-up in the present study was much longer than prior studies, unveiling the decline in risk, which may have also potentially contributed to the comparable mortality between patients with only one affected arterial bed and those without.

Comparison between PCI and CABG in patients with established CVD has not been fully investigated. Observational data from patients with PVD and multi-vessel CAD showed that revascularization with CABG led to better adjusted 3-year survival than PCI [30]. In contrast, randomised data from the BARI study showed no difference in 5 -year survival between patients with multi-vessel disease and established CVD treated with balloon angioplasty or CABG, however, this study was hampered by limited power to detect a treatment effect due to the small size of the established CVD subgroup ( $n=303 / 1816)$ [20]. In the current analysis, we observed a higher risk of 5-year MACCE with PCI compared with CABG, which was mainly driven by the higher risk of MI and repeat revascularization (Table 3); no difference was observed in 5-year all-cause death. Similarly, at 10 years, PCI had a non-significant numerically higher risk of all-cause death compared with CABG. The SYNTAX score II 2020 was derived from the SYNTAXES population, and PVD was identified as a prognostic factor [31]. The non-significant difference in outcomes between PCI and CABG may also, therefore, be because PVD, which is only one component of established CVD, had a limited sample size $(n=175)$, such that the high crude mortality at 10 years did not remain significant after adjustment for confounders. More importantly, we found that in contrast to the neutral "average treatment effect" observed in patients with established CVD at 10 years with either CABG or PCI, the SYNTAX score II 2020 clearly identifies individuals who derive a treatment-specific survival benefit.

\section{Limitations}

Although the SYNTAXES trial is one of the largest trials comparing PCI and CABG in complex CAD, it may not have adequate statistical power to produce reliable evidence for subgroup analyses [32]. There was no formal correction for multiple testing for subgroup analyses in the trial, considering the post hoc nature of the analysis [33]. Therefore, the reported results should be interpreted as exploratory and hypothesis-generating only. The randomisation in the SYNTAX trial was not stratified according to established CVD. Therefore, imbalances exist between groups. Although we performed adjustment for confounders, the inability to include all relevant confounders may cause bias that cannot be adjusted. Outcomes may have been affected by the location of the established CVD [10, 34]; however, our limited sample size precluded any meaningful comparisons between affected arterial beds. Studies with larger sample sizes in this high-risk population are warranted to explore these outstanding issues. The endpoint was all-cause death only. MACE and quality-adjusted life years (QUALY) are also relevant outcomes from the patient's viewpoint [35]. However, allcause death has been considered as the most robust and unbiased index for clinical assessment, and is less likely affected by ascertainment bias [36]. Finally, in the SYNTAX study, patients received PCI with the first-generation DES, the results are, therefore, only partially applicable to the contemporary new generation of DES. However, it is unavoidable that the findings from long-term follow-up data are based on outdated technology, whilst the evidence for contemporary technology can be derived only from short-term follow-up studies. Finally, an inherent bias may exist that patients with severe established CVD, which precludes performance of PCI, may not have been included in the randomised cohort and would have probably by default been included in the CABG registry in the SYNTAX trial.

\section{Conclusion}

The presence of established CVD, especially involving more than one territory, was associated with a significantly increased risk of 10-year all-cause death. We observed acceptable long-term outcomes amongst patients with complex CAD and established CVD, suggesting that these patients should not be precluded from undergoing invasive angiography or revascularization, which could improve their morbidity and mortality. Overall, whilst there was a neutral treatment effect, the SYNTAX score II 2020 was able to identify those patients who would benefit the most from either CABG or PCI. The association between revascularization strategy and very long-term ischaemic and safety outcomes in this high-risk population needs further investigation in dedicated trials.

Supplementary Information The online version contains supplementary material available at https://doi.org/10.1007/s00392-021-01922-y.

Acknowledgements Not applicable.

Funding The SYNTAX Extended Survival study was supported by the German Foundation of Heart Research (Frankfurt am Main, Germany). The SYNTAX trial, during 0- to 5-year follow-up, was funded by Boston Scientific Corporation (Marlborough, MA, USA). Both sponsors had no role in the study design, data collection, data analyses and interpretation of the study data, nor were involved in the decision to publish the final manuscript. The principal investigators and authors 
had complete scientific freedom. This work, RW, CG and WW are supported by Science Foundation Research Professorship Award (15/ $\mathrm{RP} / 2765)$.

\section{Declarations}

Conflict of interest Dr. Hara reports a grant for studying overseas from Japanese Circulation Society, a grant-in-Aid for JSPS Fellows and a grant from Fukuda Foundation for Medical Technology. Dr. van Geuns reports grants and personal fees from Boston Scientific, grants and personal fees from Abbott Vascular, grants and personal fees from Astra Zeneca, grants and personal fees from Amgen, grants from InfraRedx, outside the submitted work. Dr. Morice reports to work as the CEO of CERC, a CRO which was never involved in the SYNTAX trial at any level, except that submitted the 10-year additional follow-up (for free) to French authorities to get approval. Dr. Morice also reports to work as minor shareholder of electroducer. Dr. Kappetein reports to work as an employee of Medtronic, outside the submitted work. Dr. Wijns reports research grant and honoraria from MicroPort; medical advisor Rede Optimus Research and co-founder Argonauts, an innovation facilitator. Dr. Serruys reports personal fees from Biosensors, Micel Technologies, Sinomedical Sciences Technology, Philips/Volcano, Xeltis, and HeartFlow, outside the submitted work. All the other authors have no disclosures.

Open Access This article is licensed under a Creative Commons Attribution 4.0 International License, which permits use, sharing, adaptation, distribution and reproduction in any medium or format, as long as you give appropriate credit to the original author(s) and the source, provide a link to the Creative Commons licence, and indicate if changes were made. The images or other third party material in this article are included in the article's Creative Commons licence, unless indicated otherwise in a credit line to the material. If material is not included in the article's Creative Commons licence and your intended use is not permitted by statutory regulation or exceeds the permitted use, you will need to obtain permission directly from the copyright holder. To view a copy of this licence, visit http://creativecommons.org/licenses/by/4.0/.

\section{References}

1. Bhatt DLSP, Ohman EM, Hirsch AT, Ikeda Y, Mas JL, Goto S, Liau CS, Richard AJ, Röther J, Wilson PW, REACH Registry Investigators (2006) International prevalence, recognition, and treatment of cardiovascular risk factors in outpatients with atherothrombosis. JAMA 295:180-189. https://doi.org/10.1001/jama. 295.2.180

2. Fernandez-Friera L, Penalvo JL, Fernandez-Ortiz A et al (2015) Prevalence, vascular distribution, and multiterritorial extent of subclinical atherosclerosis in a middle-aged cohort: the PESA (Progression of Early Subclinical Atherosclerosis) Study. Circulation 131(24):2104-2113. https://doi.org/10.1161/CIRCULATIO NAHA.114.014310

3. Bhatt DL, Peterson ED, Harrington RA et al (2009) Prior polyvascular disease: risk factor for adverse ischaemic outcomes in acute coronary syndromes. Eur Heart J 30(10):1195-1202. https://doi. org/10.1093/eurheartj/ehp099

4. Bhatt DLEK, Ohman EM, Hirsch AT, Goto S, Mahoney EM, Wilson PW, Alberts MJ, D'Agostino R, Liau CS, Mas JL, Röther J, Smith SC Jr, Salette G, Contant CF, Massaro JM, Steg PG, REACH Registry Investigators (2010) Comparative determinants of 4-year cardiovascular event rates in stable outpatients at risk of or with atherothrombosis. JAMA 304:1350-1357. https://doi.org/ 10.1001/jama.2010.1322

5. Jukema JW, Szarek M, Zijlstra LE et al (2019) Alirocumab in patients with polyvascular disease and recent acute coronary syndrome: ODYSSEY OUTCOMES Trial. J Am Coll Cardiol 74(9):1167-1176. https://doi.org/10.1016/j.jacc.2019.03.013

6. Zeymer U, Parhofer KG, Pittrow D et al (2009) Risk factor profile, management and prognosis of patients with peripheral arterial disease with or without coronary artery disease: results of the prospective German REACH registry cohort. Clin Res Cardiol 98(4):249-256. https://doi.org/10.1007/s00392-009-0754-1

7. Gutierrez JA, Aday AW, Patel MR, Jones WS (2019) Polyvascular disease: reappraisal of the current clinical landscape. Circ Cardiovasc Interv 12(12):e007385. https://doi.org/10.1161/CIRCI NTERVENTIONS.119.007385

8. Morikami Y, Natsuaki M, Morimoto T et al (2013) Impact of polyvascular disease on clinical outcomes in patients undergoing coronary revascularization: an observation from the CREDO-Kyoto Registry Cohort-2. Atherosclerosis 228(2):426-431. https://doi. org/10.1016/j.atherosclerosis.2013.04.005

9. Miura T, Soga Y, Doijiri T et al (2013) Prevalence and clinical outcome of polyvascular atherosclerotic disease in patients undergoing coronary intervention. Circ J 77(1):89-95. https://doi.org/ 10.1253/circj.cj-12-0535

10. Kobo O, Contractor T, Mohamed MO et al (2020) Impact of preexistent vascular and poly-vascular disease on acute myocardial infarction management and outcomes: an analysis of 2 million patients from the National Inpatient Sample. Int J Cardiol. https:// doi.org/10.1016/j.ijcard.2020.11.051

11. van der Meer MG, Cramer MJ, van der Graaf Y et al (2014) The impact of polyvascular disease on long-term outcome in percutaneous coronary intervention patients. Eur J Clin Invest 44(3):231239. https://doi.org/10.1111/eci.12222

12. Garg S, Chichareon P, Kogame N et al (2020) Impact of established cardiovascular disease on outcomes in the randomized global leaders trial. Catheter Cardiovasc Interv 96(7):1369-1378. https://doi.org/10.1002/ccd.28649

13. Thuijs DJFM, Kappetein AP, Serruys PW et al (2019) Percutaneous coronary intervention versus coronary artery bypass grafting in patients with three-vessel or left main coronary artery disease: 10-year follow-up of the multicentre randomised controlled SYNTAX trial. The Lancet 394(10206):1325-1334. https://doi.org/10. 1016/s0140-6736(19)31997-x

14. Ong AT, Serruys PW, Mohr FW et al (2006) The SYNergy between percutaneous coronary intervention with TAXus and cardiac surgery (SYNTAX) study: design, rationale, and run-in phase. Am Heart J 151(6):1194-1204. https://doi.org/10.1016/j. ahj.2005.07.017

15. Serruys PWMM, Kappetein AP, Colombo A, Holmes DR, Mack MJ, Stahle E, Feldman TE, van den Brand M, Bass EJ, Van Dyck N, Leadley K, Dawkins KD, Mohr FW, Investigators S (2009) Percutaneous coronary intervention versus coronary-artery bypass grafting for severe coronary artery disease. N Engl J Med 360:961-972

16. Mohr FW, Morice M-C, Kappetein AP et al (2013) Coronary artery bypass graft surgery versus percutaneous coronary intervention in patients with three-vessel disease and left main coronary disease: 5-year follow-up of the randomised, clinical SYNTAX trial. The Lancet 381(9867):629-638. https://doi.org/10. 1016/s0140-6736(13)60141-5

17. Pocock SJ, McMurray JJV, Collier TJ (2015) Statistical controversies in reporting of clinical trials: part 2 of a 4-part series on statistics for clinical trials. J Am Coll Cardiol 66(23):2648-2662. https://doi.org/10.1016/j.jacc.2015.10.023

18. Wang R, Serruys PW, Gao C et al (2021) Ten-year all-cause death after percutaneous or surgical revascularization in diabetic 
patients with complex coronary artery disease. Eur Heart J 2021 ehab441. Online ahead of print. https://doi.org/10.1093/eurheartj/ ehab441

19. Eagle KA, Rihal CS, Foster ED, Mickel MC, Gersh BJ (1994) Long-term survival in patients with coronary artery disease: importance of peripheral vascular disease. The Coronary Artery Surgery Study (CASS) Investigators. J Am Coll Cardiol 23(5):1091-1095. https://doi.org/10.1016/0735-1097(94)90596-7

20. Sutton-Tyrrell K, Rihal C, Sellers MA et al (1998) Long-term prognostic value of clinically evident noncoronary vascular disease in patients undergoing coronary revascularization in the Bypass Angioplasty Revascularization Investigation (BARI). Am J Cardiol 81(4):375-381. https://doi.org/10.1016/s0002-9149(97) 00934-X

21. Libby P, Ridker PM, Hansson GK, Leducq Transatlantic Network on A (2009) Inflammation in atherosclerosis: from pathophysiology to practice. J Am Coll Cardiol 54(23):2129-2138. https://doi. org/10.1016/j.jacc.2009.09.009

22. Libby P, Buring JE, Badimon L et al (2019) Atherosclerosis. Nat Rev Dis Primers 5(1):56. https://doi.org/10.1038/ s41572-019-0106-z

23. Hibi K, Kimura T, Kimura $\mathrm{K}$ et al (2011) Clinically evident polyvascular disease and regression of coronary atherosclerosis after intensive statin therapy in patients with acute coronary syndrome: serial intravascular ultrasound from the Japanese assessment of pitavastatin and atorvastatin in acute coronary syndrome (JAPANACS) trial. Atherosclerosis 219(2):743-749. https://doi.org/10. 1016/j.atherosclerosis.2011.08.024

24. Modolo R, Tateishi H, Miyazaki Y, Pighi M, Abdelghani M, Roos MA, Wolff Q, Wykrzykowska JJ, de Winter RJ, Piazza N, Richardt G, Mohamed Abdel-Wahab O, Soliman YO, Van Mieghem NM, Serruys PW (2019) Quantitative aortography for assessing aortic regurgitation after transcatheter aortic valve implantation: results of the multicentre ASSESS-REGURGE Registry. EuroIntervention 15:420-426

25. Subherwal S, Bhatt DL, Li S et al (2012) Polyvascular disease and long-term cardiovascular outcomes in older patients with non-STsegment-elevation myocardial infarction. Circ Cardiovasc Qual Outcomes 5(4):541-549. https://doi.org/10.1161/CIRCOUTCOM ES.111.964379

26. Nakamura T, Toda K, Miyagawa S et al (2016) Symptomatic peripheral artery disease is associated with decreased long-term survival after coronary artery bypass: a contemporary retrospective analysis. Surg Today 46(11):1334-1340. https://doi.org/10. 1007/s00595-016-1379-4
27. Chu D, Bakaeen FG, Wang XL et al (2008) The impact of peripheral vascular disease on long-term survival after coronary artery bypass graft surgery. Ann Thorac Surg 86(4):1175-1180. https:// doi.org/10.1016/j.athoracsur.2008.06.024

28. Alberts MJ, Bhatt DL, Mas JL et al (2009) Three-year follow-up and event rates in the international REduction of Atherothrombosis for Continued Health Registry. Eur Heart J 30(19):2318-2326. https://doi.org/10.1093/eurheartj/ehp355

29. Volis I, Saliba W, Jaffe R, Eitan A, Zafrir B (2020) Effect of cerebrovascular and/or peripheral artery disease with or without attainment of lipid goals on long-term outcomes in patients with coronary artery disease. Am J Cardiol 128:28-34. https://doi.org/ 10.1016/j.amjcard.2020.04.043

30. O'Rourke DJ, Quinton HB, Piper W et al (2004) Survival in patients with peripheral vascular disease after percutaneous coronary intervention and coronary artery bypass graft surgery. Ann Thorac Surg 78(2):466-470. https://doi.org/10.1016/j.athoracsur. 2004.01.044 (discussion 70)

31. Takahashi K, Serruys PW, Fuster V et al (2020) Redevelopment and validation of the SYNTAX score II to individualise decision making between percutaneous and surgical revascularisation in patients with complex coronary artery disease: secondary analysis of the multicentre randomised controlled SYNTAXES trial with external cohort validation. Lancet 396(10260):1399-1412. https:// doi.org/10.1016/S0140-6736(20)32114-0

32. Rothwell PM (2005) Treating individuals 2. Subgroup analysis in randomised controlled trials: importance, indications, and interpretation. Lancet 365(9454):176-186. https://doi.org/10.1016/S01406736(05)17709-5

33. Li G, Taljaard M, Van den Heuvel ER et al (2017) An introduction to multiplicity issues in clinical trials: the what, why, when and how. Int J Epidemiol 46(2):746-755. https://doi.org/10.1093/ije/ dyw 320

34. Achterberg S, Cramer MJ, Kappelle LJ et al (2010) Patients with coronary, cerebrovascular or peripheral arterial obstructive disease differ in risk for new vascular events and mortality: the SMART study. Eur J Cardiovasc Prev Rehabil 17(4):424-430. https://doi.org/10.1097/HJR.0b013e3283361ce6

35. Stolker JM, Spertus JA, Cohen DJ et al (2014) Rethinking composite end points in clinical trials: insights from patients and trialists. Circulation 130(15):1254-1261. https://doi.org/10.1161/ CIRCULATIONAHA.113.006588

36. Lauer MSBE, Young JB, Topol EJ (1999) Cause of death in clinical research: time for a reassessment? J Am Coll Cardiol 34:618-620 